FACULdADE DE CIÊNCIAS ECONÔ MICAS DA UFRGS

MACROECONOMIA DO BRASIL PÓS-1994 LUIZ CARLOS BRESSER-PEREIRA

DESENVOLVIMENTO ECONOMMICO, PREFERÊNCIA PELA LIQUIDEZ E ACESSO BANCÁRIO: UM ESTUDO DE CASO DAS MESORREGIÓES DE MINAS GERAIS

MARCO CROCCO, CLAUDIO BARRA DE CASTRO, ANDERSON CAVALCANTE E VANESSA DA COSTA VAL

FRIEDMAN E O MONETARISMO: A VELHA TEORIA QUANTITATIVA DA MOEDA E A MODERNA ESCOLA MONETARISTA

GENTIL CORAZZAE RODRIGO L. KREMER

BOLLHAS RACIONAIS, CICLO DE PREÇOS DE ATIVOS E RACIONALIDADE LIMITADA: UMA AVALIACAOO CRITICA DOS MODELOS NEOCLÁSSICOS DE BOLHAS ESPECULATIVAS JOSÉ LUIS OREIRO

VULNERABILITY INDICATORS OF THE TWIN CRISES: THE EAST ASIAN EPISODE

TITO BELCHIOR SILVA MOREIRA

IMPACTOS POTENCIAIS DA NEGOCIAÇÃO DA ALCA SOBRE OS INVESTIMENTOS EXTERNOS EM SERVIÇOS PROFISSIONAIS NO BRASIL

MICHEL ALEXANDRE, OTAVIANO CANUTO E GILBERTO TADEU LIMA

TEORIA MARXISTA DO VALOR: UMA INTRODUÇẢO ALFREDO SAAD FILHO

UM ESTUDO EMPIRICO DOS CICLOS POLITICO. ECONOOMICOS NO BRASIL

ATHOS PRATES DA SILVEIRA PREUSSLER E MARCELO SAVINO PORTUGAL

RELENDO CHANDLER, WILLIAMSON E NORTH PARA ENTENDER O PROCESSO DE FORMACĀO DAS ESTRADAS DE FERRO NO BRASIL

JEFFERSON ANDRONIO RAMUNDO STADUTO

WEIMAR FREIRE DA ROCHA IR. E CLAIITON ATAIDES DE FREITAS

MATRIZ DE INSUMO-PRODUTO PARA A ECONOMIA TURISTICA BRASILEIRA: CONSTRUCCÃO E ANÁLISE DAS RELAÇÓES INTERSETORIAIS

FRANCISCO CASIMIRO FILHO E JOAQUIM JOSÉ MARTINS GUILHOTO

SEÇĀO ESPECIAL: AVALIAÇŌES INICIAIS DA POLITTICA ECONÓMICA DO GOVERNO LULA

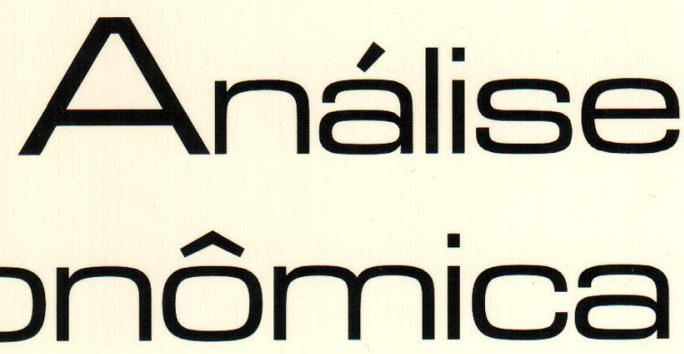


Universidade Federal do Rio Grande do Sul

Reitora: Profa. Wrana Maria Panizzi

Faculdade de Ciencias EConómicas

Diretora: Prof Pedro César Dutra Fonseca

Centro de Estudos e Pesquisas Economicas

Diretor: Prof. Gentil Corazza

Departamento de Ciéncias económicas

Chiefe: Prof. Ricardo Dathein

Curso de Pós. Graduação em Economia

Coordenador: Prof. Eduardo Pontual Ribeiro

Programa de Pós-Graduação em Desenvolvimento Rural

Coordenador: Prof. jalcione Almeida

CONSElHo EDITORIAL:

Carlos G. A. Mielitz Netto (UFRGS), Eduardo A. Maldonado Filho (UFRGS), Eduardo P. Ribeiro (UFRGS), Eleutério F. S. Prado (USP), Eugênio Lagemann (UFRGS), Fernando Cardim de Carvalho (UFRJ), Fernando Ferrari Filho (UFRGS), Fernando de Holanda Barbosa (FGV/RJ), Flávio Vasconcellos Comim (UFRGS), Gentil Corazza (UFRGS), Giácomo Balbinotto Netto (UFRGS), Gustavo Franco (PUC/RJ), Jan A. Kregel (UNCTAD), João Rogério Sanson (UFSC), Joaquim Pinto de Andrade (UnB), Jorge Paulo Araújo (UFRGS), Marcelo S. Portugal (UFRGS), Maria Alice Lahorgue (UFRGS), Paul Davidson (University of Tennessee), Paulo D. Waquil (UFRGS), Pedro C. D. Fonseca (UFRGS), Philip Arestis (Levy Economics Institut of Bard College), Roberto C. de Moraes (UFRGS), Ronald Otto Hillbrecht (UFRGS), Sabino da Silva Porto Jr. (UFRGS), Stefano Florissi (UFRGS) e Werner Baer (University of Illinois at UrbanaChampaign).

COMISSÃO EDITORIAL:

Eduardo Augusto Maldonado Filho, Fernando Ferrari Filho, Gentil Corazza, Marcelo Savino Portugal, Paulo Dabdab Waquil e Roberto Camps Moraes.

EDIroR: Prof. Fernando Ferrari Filho

Editor Adunnio: Prof. Gentil Corazza

SECRETÁrla: Clarissa Roncato Baldim

REVISÁO DE TEXTOS: Vanete Ricacheski

EDITORaÇão Eletrónica: Vanessa Hoffmann de Quadros

Fundador: Prof Antônio Carlos Santos Rosa

Os materiais publicados na revista Análise Econômica são da exclusiva responsabilidade dos autores. É permitida a reprodução total ou parcial dos trabalhos, desde que seja citada a fonte. Aceita-se permuta com revistas congêneres. Aceitam-se, também, livros para divulgação, elaboraçāo de resenhas e recensōes Toda correspondência, material para publicaçāo (vide normas na terceira capa), assinaturas e permutas devem ser dirigidos ao seguinte destinatário:

Análise Econômico

PROF FERNANDO FERRARI FILHO Revisła Análise Econômica - Av. João Pessoa, 52 CEP 90040-000 PORTO ALEGRE - RS, BRASL Telefones: (051) 316-3513 - Fax: (051) 316-3990 E-mail: rae@ufrgs.br

Ano 21, $n^{\circ} 39$, março, 2003 - Porto Alegre

Faculdade de Ciências Econômicas, UFRGS, 2003

Periodicidade semestral, março e setembro.

Tiragem: 500 exemplares

1. Teoria Econômica - Desenvolvimento Regional.

Economia Agrícola - Pesquisa Teórica e Aplicada -

Periódicos. I. Brasil

Faculdade de Ciências Econômicas,

Universidade Federal do Rio Grande do Sul 


\title{
Relendo Chandler, Williamson e North para entender o processo de formação das estradas de ferro no Brasil
}

\author{
Jefferson Andronio Ramundo Staduto ${ }^{I}$ \\ Weimar Freire da Rocha Jr. ${ }^{1}$ \\ Clailton Ataides de Freitas ${ }^{2}$
}

\begin{abstract}
This paper examines the process of creation of the great and "modern" Brazilian railway companies in the century XIX, highlighting specially, São Paulo railway companies that appeared harnessed to the coffee economy. This exam is accomplished to the mode of some of the theorical approaches of the Chandler, Williamson, North and others.
\end{abstract}

Key words: railway companies; vertical integration; Brazilian economy JEL Classification: L. L.2. L.22

\section{Introdução}

O objetivo central deste estudo é analisar a criação e a expansão das empresas ferroviárias brasileiras na segunda metade do século XIX, sob a ótica das abordagens desenvolvidas por Chandler (1962, 1977), Williamson (1975, 1985, 1996) e North (1994). Nesse sentido, primeiramente, examinam-se algumas particularidades da formação da empresas ferroviárias brasileiras. Em segundo lugar, revê-se a aplicabilidade da análise de Chandler $(1962,1977)$ para o caso brasileiro. Em terceiro, discute-se o processo de criação das empresas ferroviárias brasileiras, sob a ótica do ambiente institucional de North (1990) e da teoria dos custos de transação e da integração vertical de Williamson (1985). Os fundamentos teóricos de Williamson são particularmente importantes para entender o papel desempenhado pelos cafeicultores na criação da malha ferroviária, como a estratégia de integração vertical entre a produção de café e o seu transporte até o Porto de Santos.

\footnotetext{
${ }^{1}$ Professores adjuntos da Universidade Estadual do Oeste do Paraná (UNIOESTE) - Campus Toledo - Rua da Faculdade, 650, Jd. La Salle, CEP 85903-000, Toledo - PR. Membros do GEPEC.E-mails: staduto@unioeste.br; wrocha@unioeste.br.

${ }^{2}$ Professor adjunto do Departamento de Economia da UFSM. E-mail: caf@ccsh.ufsm.br
} 
Ao enfatizar os aspectos históricos da criação das grandes corporações e, em especial, das empresas ferroviárias e telegráficas norte-americanas, as contribuições de Chandler (1977) tornam-se fundamentais. Este autor descreve com surpreendente riqueza de detalhes o surgimento bem como a estrutura organizativa dessas empresas nos Estados Unidos, em meados do século XIX.

A formaçăo das empresas ferroviárias brasileiras ocorre na segunda metade do século XIX, portanto muito próxima ao período de surgimento das ferrovias nos Estados Unidos. Essa proximidade temporal permite levantar um olhar especulativo, para comparar, nas suas nuances e particularidades, as experiências brasileira e norteamericana no setor de Transporte Ferroviário.

É importante destacar que as contribuições de Chandler, para entender o caso brasileiro, podem ser consideradas, de certa forma, limitadas, em virtude de o autor não ter examinado o papel do Estado e do fator humano em seu modelo analítico. Conforme é destacado na seção 2, o Estado teve papel fundamental na formação da empresas ferroviárias brasileiras. Nesse sentido, procurando complementar a abordagem de Chandler para entender o caso brasileiro, busca-se amparo teórico em North (1990). A partir da concepção teórica deste autor, no que se refere ao papel das instituições, é possivel entender de forma mais acurada a criação das empresas ferroviárias brasileiras.

Seguindo a abordagem de Williamson (1985), a qual se baseia nos atributos de transação, investiga-se se houve intenção dos produtores rurais de café em integrar verticalmente suas atividades, quando decidiram tornar-se os principais acionistas das empresas ferroviárias.

Para abordar de forma sistemática os objetivos previamente definidos, dividiu-se o presente trabalho em cinco seçōes, incluindo esta introdução. A seção 2 está dividida em três partes: a primeira corresponde a um breve panorama da criação das ferrovias no Brasil; a segunda é uma introdução da relação entre a economia cafeeira e as ferrovias brasileiras; e a terceira analisa o surgimento das empresas de estrada de ferro no Estado de São Paulo. O enfoque está centrado na discussão analítica do panorama histórico. Na seção 3 , são apresentadas as contribuições teóricas dos autores anteriormente mencionados, para elucidar a temática do trabalho. Na seção 4, procura-se interpretar analiticamente o surgimento das empresas ferroviárias no Brasil. Na última seção, há conclusões sobre as contribuiçóes das abordagens que permeiam o presente trabalho. 


\section{O Processo Histórico de Formação das Ferrovias no Brasil}

2.1 Aspectos políticos e econômicos da formação das ferrovias brasileiras

Em 1835, surgiu a primeira Lei Geral autorizando o Governo Imperial a abrir concessões públicas para a construção de estradas de ferro ligando o Rio de Janeiro às capitais das províncias de Minas Gerais, Rio Grande do Sul e Bahia. Na Província de São Paulo, em 1836, a Assembléia Legislativa Provincial fez a primeira concessão específica de estrada de ferro, cujo intuito era tranportar o açúcar para o Porto de Santos. Ficava clara a orientação econômica existente na concessão das linhas férreas. No entanto, esses primeiros concessionários não foram capazes de organizar uma companhia para a contrução e exploração das estradas de ferro (MÁTOS, 1974).

De acordo com Saes (1986), o lançamento da via férrea brasileira ocorre verdadeiramente em 1852. Efetiva-se o início da cons. trução de cinco linhas de estrada de ferro: a estrada de ferro $D$. Pedro II (do Rio de Janeiro a São Paulo), a de Mauá, a de Recife ao São


Segundo Saes (1986), dessas cinco estradas, duas vinculam-se tipicamente ao café - estradas D. Pedro II e de Santos a Jundiaí. A estrada de ferro de Mauá serviu, temporariamente, ao café do Vale do Paraíba fluminénse; já as outras duas - na Bahia e em Pernambuco - nào tinham vínculos com a produção de café. Verifica-se que os traçados das linhas férreas propostos em 1935 de ligar as capitais das principais províncias ao Rio de Janeiro não foram efetivados.

O grande estímulo para a formação da viação férrea brasileira foi a Lei Feijó, de 1852. Essa lei, com a "Garantia de Juros" pelo Governo Imperial, concedia juros de $5 \%$ a.a. para os capitais despendidos na construção da linha. Em geral, eram acrescidos mais $2 \%$ de juros a esses capitais, concedidos pelos governos das províncias. A concessão dessas estradas, em geral, era obtida por empresários com influência política no Império.

Uma vez de posse da concessão, o empresário agraciado poderia obter ganhos de capital caso repassasse a outros empresários tal concessão.

Esse incentivo, levado a cabo com a Lei Feijó, procurava evitar a ruptura contratual, pois as concessões tinham como imposição a exe- 
cução da construção da estrada de ferro em prazos preestabelecidos. A primeira concessão de linha férrea, com início no Rio de Janeiro em direção a São Paulo (D.... Pedro II), foi dada a Thomas Cochranre, em 1840. Durante toda essa década, o mencionado empresário não conseguiu organizar uma companhia para a construção da linha (BAPTISTA, 1942 apud SAES, 1986).

Apesar de todas as amarrações jurídicas e dos incentivos explícitos na Lei Feijó, a primeira tentativa de construção da estrada de ferro D. Pedro II fracassou, sendo necessária a intervenção direta do Governo Imperial, pela subscrição de ações no mercado financeiro e a reorganização administrativa da empresa, em 1855. Dessa forma, a construção da respectiva estrada assumiu caráter privado, mas com estreitos vínculos com o Governo Imperial, pois parte dos recursos provinha do Tesouro. Além disso, cabia ao imperador indicar um diretor (embora nunca o tivesse feito), sendo os demais diretores eleitos pelas assembléias de acionistas majoritários. A maioria desses acionistas estava vinculada ao comércio e ao setor bancário (SAES, 1986).

O desenvolvimento da estrada de ferro, como companhia particular, conjugou a situação de quase permanente escassez de recursos e sérios problemas com a construção da linha, agravando-se de tal forma que o resultado final foi a dissolução da companhia, a qual passou para o domínio do Estado, constituindo, portanto, um fracasso empresarial. Este decorreu, em primeiro lugar, devido ao distanciamento dos principais acionistas da direção da companhia; e, em segundo, da incapacidade de carrear novos recursos para a empresa, entre outros aspectos ${ }^{3}$.

Ainda, segundo Saes (1986), os acionistas, todos oriundos do Rio de Janeiro e de origem "mercantil", tinham investido em ferrovias apenas como uma aplicação financeira e esperavam lucros imediatos e compensadores. Diante da frustração do seu empreendimento, devido ao caráter de longo prazo do investimento, os acionistas aceitaram, sem maior oposição, a troca compulsória das ações da companhia por apólices do Governo com $6 \%$ a.a. de juros.

${ }^{3}$ Como observa Saes (1986, p. 30), "O próprio C. B. Ottoni, principal dirigente da empresa, durante os dez anos de vida privada, se dizia ignorante dos problemas técnicos de ferrovias [...]. Nota-se, também, a incapacidade ou o desinteresse desses principais acionistas em apoiarem a obtenção de novos recursos". 


\subsection{A economia cafeeira e as ferrovias brasileiras}

Em torno da economia cafeeira no Brasil, criou-se uma infraestrutura de apoio que a sustentou e que, por sua vez, transbordou para outros setores da economia nacional. O período de expansão vigorosa da cultura do café ocorreu a partir de 1850 e prolongou-se até 1880. Esse período foi de suma importância, especialmente para o Estado de São Paulo, pois, mesmo com as crises freqüentes do preço do produto no mercado externo, constatou-se uma intensa mobilização, pelas instituições ${ }^{4}$ brasileiras, na figura do Estado, para manter os ganhos financeiros desse setor. O café representava para o Brasil, como se sabe, a sua principal fonte de divisa.

As políticas públicas em defesa do café ocorreram, praticamente, ao longo de todo o ciclo desse produto. Contudo, foram mais sistemáticas e efetivas a partir do Acordo de Taubaté, em 1906. Com o agravamento da crise cafeeira, a partir dos anos 30, fruto da depressão da economia norte-americana, o Brasil adotou mecanismos de sustentação de preço desse produto no mercado internacional, de dimensões pouco conhecidas até então na economia mundial.

Essa distorção de política econômica teve reflexos importantes e profundos em toda a economia brasileira. Pode-se perceber, nitidamente, que as medidas econômicas tomadas ao longo do ciclo do café foram seletivas e excludentes; seletivas, porque visavam a garantir, especificamente, a rentabilidade dos cafeicultores; e excludentes, porque beneficiavam diretamente as regiōes produtoras de café em detrimento de outras áreas do país.

Segundo Delfim Netto (1959), da primeira metade do século XIX até o início do século XX, o preço do café sofreu grandes flutuações, por ser extremamente vulnerável às oscilações externas. Tais flutuações foram anuladas por políticas cambiais que mantiveram a rentabilidade do produtor. Devido às sucessivas crises de preços a partir dos anos 30, alguns setores da economia acabaram sofrendo declínio ou estagnação, como, por exemplo, o setor ferroviário. Em razão dessa crise, muitas empresas férreas foram estatizadas. O período de expansão da malha ferroviária no Estado de São Paulo, por volta de 1860 a 1930, esteve extremamente relacionado com a dinâmica da cultura do café, como fica evidente na Tabela 1; crescendo até meados dos anos 30 e estagnando a partir dessa data.

${ }^{4}$ Na próxima seção, discutem-se com mais detalhes as instituições segundo North $(1990,1991$, 1994). 
Tabela 1: Extensão da Malha Ferroviária no Brasil e em São Paulo (km)

\begin{tabular}{cccc}
\hline Ano & Brasil & SãoPaulo & $\begin{array}{c}\text { São Paulo/Brasil } \\
(\%)\end{array}$ \\
\hline 1854 & 14 & - & - \\
1865 & 498 & - & \\
1875 & 1.801 & 1.212 & 67,3 \\
1885 & 6.930 & 2.425 & 35,0 \\
1895 & 12.967 & 2.962 & 22,8 \\
1905 & 16.781 & 3.842 & 24,2 \\
1915 & 26.647 & 6.293 & 23,6 \\
1925 & 30.731 & 6.823 & 22,2 \\
1935 & 33.331 & 7.366 & 22,1 \\
1994 & 30.396 & 6.434 & 21,2 \\
\hline
\end{tabular}

Fonte: Saes (1981), para os anos de 1854 a 1935; Anuário Estatístico do Brasil - IBGE (1996), segunda coluna do ano de 1994; e Anuário Estatístico do Estado de São Paulo - SEADE (1995), terceira coluna do ano de 1994.

Os investimentos em estrada de ferro são vultosos e exigem longos períodos de maturação. Devido a essas peculiaridades, e também em razão do caráter imediatista da maioria do empresariado brasileiro no século XIX, tais empreendimentos não atraíram muitos investidores. Dessa forma, exigiram-se maciços investimentos do Governo Federal para que os projetos das estradas de ferro fossem viabilizados. No entanto, conforme Topik (1987), a Província de São Paulo não foi privilegiada com recursos públicos na mesma intensidade da sua importância econômica. No entendimento das autoridades governamentais, o próprio dinamismo da economia paulista seria suficiente para atrair os investidores nacionais e estrangeiros. De fato, as empresas ferroviárias paulistas surgiram no âmbito da própria dinâmica da cultura cafeeira, na então Província de São Paulo, a partir da segunda metade do século XIX. Realmente, pôdese constatar uma menor intervenção governamental na expansão das empresas ferroviárias paulistas, mas, por outro, o Governo não foi nada parcimonioso em assegurar a expansão da cultura do café, visto que o crescimento dessas empresas estava estreitamente atrelado ao comportamento do setor cafeeiro. 


\subsection{As origens históricas das ferrovias paulistas ${ }^{5}$}

As empresas ferroviárias surgiram em período de grandes transformações institucionais no Brasil, tais como suspensão do tráfico de escravos em 1850, abolição da escravatura em 1888, imigração de mão-de-obra européia, proclamação da República e o encilhamento. No campo tecnológico, inovações como as máquinas a vapor, o telégrafo e o trem de ferro, entre outras, já eram dis poníveis.

A cultura do café motivada pela elevação dos preços internacionais, a partir da segunda metade do século XIX, expandiu-se rapidamente, imprimindo uma "marcha" para o oeste paulista. Isso significava que a produção estava distanciando-se do Porto de Santos. O transporte do café era feito por meio de tropas de mulas, da fazenda até esse porto. Os animais eram dos próprios fazendeiros e de terceiros, e, naturalmente, com o volume da produção aumentando e as distâncias crescendo, o transporte tornava-se moroso e dispendioso, o que resultava em muitos desperdícios de carga ao longo do caminho percorrido. Diante dessas circunstâncias, começou a amadurecer concretamente a idéia de se construir uma linha férrea que ligasse as regiões produtoras de café ao Porto de Santos.

Tinha-se na superação da Serra do Mar, o trecho Santos-Jundiaí, a tarefa mais árdua para escoar a produção do café do planalto paulista. Em 1856, a concessão dessa primeira etapa foi dada ao Barão de Mauá, ao Marquês de Monte Alegre e ao Conselheiro Pimenta Bueno, a fim de incorporar uma companhia estrangeira.

A construção da linha iniciou-se em 1860, depois da transferência da concessão à companhia inglesa São Paulo Railway Limited. Assim, essa empresa foi responsável pela construção da primeira ferrovia paulista. A companhia inglesa, apesar de possuir a preferência de estender a linha para o interior do estado, não se interessou em fazê-lo. A literatura não deixa claros os motivos desse desinteresse, e, neste sentido, Veiga (1991) destaca a ausência de bibliografia sobre a São Paulo Railway Limited. Toda produção dirigida ao Porto de Santos teria de ser feita por essa ferrovia. Na condição de quase monopólio, evidenciava-se um plano estratégico dessa empresa para evitar os riscos inerentes a qualquer investimento em

\footnotetext{
${ }^{5}$ A abordagem teórica desta seção baseia-se em Saes (1986), e no caso da Companhia Paulista também se baseou em Debes (1968). As exceções são citadas no texto.
} 
economia de mercado. Enquanto os produtores rurais assumiam os riscos inerentes da produção agrícola e mais os riscos de mercado advindos das flutuações de preço do café, os acionistas da Cia. São Paulo Railway estavam atuando em um ambiente econômico, praticamente sem riscos, já que ela podia administrar o preço que deveria ser cobrado para transportar o café até o porto. Naturalmente, os preços eram fixados para gerar lucro econômico puro.

Entre os anos de 1868 a 1880, registraram-se 26 novas sociedades, a maioria das quais era constituída por empresas de grande porte. Entre as empresas, encontravam-se quatro de estrada de ferro: a Cia. Paulista, a Cia. Ituana, a Cia. Mojiana e a Cia. Sorocabana. Nesse período foi intensa a formação de sociedades em São Paulo, pois, até 1868, havia apenas duas empresas formadas por associação.

As companhias Paulista, Ituana e Mojiana tinham em comum o fato de os seus maiores acionistas estarem ligados à produção do café, enquanto a companhia Sorocabana tinha os seus acionistas ligados ao setor não-agrícola, isto é, ao setor "mercantil". Portanto, a construção das linhas férreas para o interior do estado, viabilizando o transporte do café das regiōes produtoras para o "pé da Serra do Mar", ficava, preponderantemente, a cargo dos fazendeiros.

A extensão da linha férrea para o interior do estado, em seu trecho inicial Jundiaí-Campinas, foi construída por acionistas de São Paulo, formando a Companhia Paulista, em 1868. O primeiro relatório dessa companhia indicou a existência de 25.000 ações distribuídas entre 654 subscritores. Por esses números, configura-se o surgimento da grande e moderna empresa acionária, que coexistia com as empresas familiares no Brasil-colônia. Havia alguns acionistas com grande número de ações, embora nenhum deles tivesse sozinho mais do que $4 \%$ delas. Os nove maiores acionistas detinham pouco mais de $20 \%$ do total das ações, e, caso incluam-se nesta relação irmãos e filhos, o número total das ações elevava-se para um pouco mais de $30 \%$ do capital subscrito. Todos esses maiores acionistas tinham origem inequívoca no setor agrícola e, em particular, na produção de café no oeste paulista.

A Companhia Mojiana tinha grande número de acionistas, um total de 315 para as 10.373 ações, estando os maiores acionistas também ligados à produção do café. Há menos informações sobre a Companhia Ituana do que a respeito das outras duas, mas essa companhia era dominada por famílias de fazendeiros com influência política na região. 
Como já mencionado, a quarta estrada de ferro, a Companhia Sorocabana, tinha um perfil diferenciado das três descritas anteriormente. Sua origem era mercantil, não estando ligada, portanto, à cafeicultura, tendo sido construída para servir prioritariamente à cultura do algodão.

$\mathrm{Na}$ região de Sorocaba, SP, na década de 1860, desenvolveu-se a cultura do algodão. Contudo, quando a estrada de ferro chegou a essa região, em 1870, essa cultura já estava economicamente em declínio. Para viabilizar o empreendimento ferroviário - que requereu vultosos investimentos --, os diretores dessa companhia começaram a financiar o plantio do algodão, apesar da tendência de queda de preço desse produto. A Companhia Sorocabana sempre enfrentou dificuldades para viabilizar-se financeiramente.

O processo de ampliação das fronteiras agrícolas por meio do avanço da cultura do café, e também do algodāo, segundo Veiga (1991), interligou-se ao movimento expansionista do capital. Esses dois elementos não foram excludentes e encontraram uma maneira de otimizar a organização empresarial, na forma de sociedade acionária. O surgimento das sociedades acionárias refletiu no processo de modernização dos cafeicultores-empresários da sociedade paulista.

Embora as quatro estradas de ferros paulistas, ligadas ao Porto de Santos, tivessem como função principal o transporte de produtos voltados à exportação, acabaram facilitando também a locomoção da população, como um objetivo secundário. Na verdade, os projetos dessas ferrovias nāo tinham, a princípio, qualquer finalidade de integração regional. A vulnerabilidade do modelo de estrada de ferro implementado no país, especialmente em São Paulo, estava no fato de estar aliado a um único produto de exportação nas regiōes produtoras.

Cabe destacar as constatações de Barat (1978), para o qual as estradas de ferro no Brasil apresentavam uma característica em comum, a de atender às necessidades de uma economia exportadora de produtos primários. As ferrovias, quase de maneira generalizada, apresentavam os seus traçados dirigidos do interior para o litoral. Dessa forma, pouco contribuíam para a integração dos mercados regionais brasileiros. Com isso, as linhas ferroviárias, com o início do processo de industrialização, mostraram-se inadequadas, pois era crescente a necessidade de transporte para o fluxo interno de bens intermediários. $O$ caso das ferrovias paulistas é uma situação 
bastante representativa do tipo de planejamento ferroviário e de traçado da malha ferroviária nacional, interior-litoral. Tais ferrovias entram em profunda crise a partir dos anos 30, cenário que é examinado com detalhe neste estudo.

\section{O Surgimento das Ferrovias no Brasil sob a Ótica do Ambiente Institucional}

Chandler (1962, 1977) pesquisou "exaustivamente" as origens históricas das modernas empresas nos EUA. Em seu trabalho publicado em 1977, o autor destaca que havia inúmeras empresas pulverizadas por todo o território norte-americano, apresentando estruturas de coordenação basicamente familiares ou com poucos proprietários. Tais empresas surgiram no limiar de 1840, quando a economia americana passou a experimentar incremento significativo do volume de atividades. Essa expansão econômica induziu o crescimento substancial de muitos empreendimentos familiares, a ponto de justificar formas de coordenações mais elaboradas, como, por exemplo, a implantação de vários níveis hierárquicos em seu processo decisório. Contudo, foi nas empresas ferroviárias e telegráficas que se pôde perceber mais nitidamente os maiores avanços ocorridos no seu sistema de coordenação. Dessa maneira, implementaram-se estruturas hierárquicas mais complexas, como a criação dos departamentos com certa autonomia de decisão e pela formação dos conselhos dos acionistas majoritários que influenciavam, pelo voto, o rumo a ser seguido pelas empresas. Essa inovação resultou em maior eficiência no monitoramento de atividades produtivas e favoreceu ainda mais o seu próprio crescimento e o estabelecimento da separação de propriedade e controle no interior das empresas.

A obra de Chandler traz, à luz dos pesquisadores, contribuições irrefutáveis, principalmente no estudo de expansão dessas corporações. O autor introduziu o conceito de estratégia de empresa e sintetizou em oito proposiçōes o seu estudo sobre a formação das modernas corporações. Na visão de Chandler (1977), a estratégia empresarial adotada nas grandes corporações assumia função muito importante, especialmente porque passaram a ter certo controle sobre a determinação dos preços dos produtos ofertados no mercado. Isso levou Chandler a dizer que "a mão invisível do mer- 
cado" começou a ser substituída pela "mão visível" das grandes corporações ${ }^{6}$.

Segundo McCraw (1998), a principal hipótese formulada por Chandler acerca da moderna empresa é a seguinte: as estratégias das empresas precipitam o surgimento de novas estruturas organizacionais. Destaca-se que essa hipótese orientou o comportamento de gerações de administradores. Analisando-se o sistema de coordenação das atividades administrativas das empresas ligadas ao transporte ferroviário brasileiro no século XIX, pode-se observar que a hipótese mencionada por Chandler permite um melhor entendimento sobre o processo e a formação e consolidação de empresas acionárias ligadas ao transporte ferroviário brasileiro, visto que o volume transportado de café era crescente e maiores eram as distâncias a serem percorridas.

Assim, a estratégia dos produtores rurais, ao criarem empresas acionárias de capital aberto, proporcionou um ambiente favorável para gestar uma estrutura de coordenação departamentalizada. Essa inovação na forma de coordenação das atividades nas empresas ferroviárias brasileiras, a exemplo do que ocorreu nos Estados Unidos, deu origem, ainda no século XIX, à moderna empresa brasileira, caracterizada pela separação entre propriedade e controle. Isso pode ser constatado observando-se os responsáveis pela administração das companhias ferroviárias, que assumiam staff de diretores. Os diretores apresentavam aos acionistas relatórios sobre o desempenho econômico-financeiro nas assembléias de acionistas.

O efeito das inovações no sistema de coordenação das empresas férreas brasileiras contribuiu para viabilizar o transporte ferroviário no Brasil. A eficiência dessa estrutura foi constatada por Saes (1981). O autor questiona a hipótese de que a falência do sistema ferroviário em São Paulo, que culminou a partir dos anos 30 com o processo de estatização, era decorrente da política administrativa adotada pelas empresas paulistas. Segundo Saes (1981), a falência desse sistema ferroviário ocorreu, sim, em razão das sucessivas crises econômicas enfrentadas pela cultura do café, o que provocou o esvaziamento da economia cafeeira paulista. O sistema de transporte ferroviário, altamente especializado no transporte de café, ficou sem um produto substituto com a mesma importância econômica deste.

- Conforme ressaltou McCraw (1998), Chandler não desconsiderava a importância das forças de mercado, mas em algumas circunstâncias as estratégias das grandes corporações eram mais imperativas do que o próprio mercado. 
Segundo McCraw (1998), as contribuições de Chandler (1977) para o estudo das modernas corporações, ressaltadas nos parágrafos anteriores, suscitam algumas críticas que podem ser agrupadas em três pontos. A primeira delas diz respeito ao papel secundário do Estado na ascensāo do capitalismo industrial; a segunda relaciona-se à ênfase dada às pesquisas de Chandler, direcionadas exclusivamente às economias dos países desenvolvidos; e a terceira está relacionada ao pouco destaque dado pelo autor ao papel do capital humano na industrialização.

As críticas identificadas por McCraw limitam e restringem, até certo ponto, a aplicação da abordagem de Chandler na interpretação da realidade brasileira? ${ }^{7}$ Muitos dos elementos que não são considerados em sua abordagem são fundamentais para compreender o surgimento das empresas ferroviárias brasileiras, como, por exemplo, o papel histórico desempenhado pelo Estado na formação da economia brasileira. Dessa maneira, considerando as limitaçōes da abordagem de Chandler (1977) para o entendimento da formação da moderna empresa ferroviária brasileira procura-se complementar o seu aporte teórico a partir das interpretaçōes de North (1990). Acredita-se que as articulaçōes dos segmentos socioeconômicos e políticos do Brasil não devam ter o seu papel reduzido, sob pena de se conceber um entendimento viesado da formação das empresas ferroviárias brasileiras.

North (1990), como um digno representante da Nova Economia Institucional (NEI), desenvolveu a construção do corpo teórico a respeito da evolução das instituições, para explicar as diferenças de desenvolvimento econômico entre os países; no entanto, gerou outras contribuições teóricas, como a definição dos termos "instituiçōes" e "organizações".

Do ponto de vista da NEI, existe o reconhecimento de que a operação e a eficiência de um sistema econômico têm suas limitações e gargalos influenciados pelo conjunto de instituições que regulam o ambiente econômico (FARINA et al., 1997).

Como as instituições se comportam, como se relacionam e de que maneiras elas estão arranjadas na sociedade é o que caracteriza a eficiência, ou não, do sistema econômico. As instituições são,

\footnotetext{
2 Uma análise mais aprofunda a partir da abordagem de Chandler $(1962,1977)$ deve ser feita considerando-se a evolução da estrutura hierárquica ou organograma das empresas de ferro concomitantemente à expansão da malha ferroviária.
} 
então, responsáveis pelo desempenho econômico das sociedades e de sua evolução (NORTH, 1994). Uma primeira definição de instituição diz que ela congrega os elementos que promovem a manuten. ção dos direitos de propriedade ${ }^{8}$ em uma sociedade, que busca promover a eficiência ótima de Pareto ${ }^{9}$, o que nem sempre ocorre.

Uma segunda definição de instituições é que estas seriam as regras formais, restriçōes informais e características do cumprimento de ambas. Seriam os sistemas de restrições que cada ser humano impõe ao tratar com os sernelhantes, as estruturas das interações políticas, econômicas e sociais. Ambas as categorias de instituições, formais e informais, de maneira conjunta, definem as estruturas de incentivo e especificidade das economias (NORTH, 1991, 1994). Existem, em toda a sociedade, por mais primitiva que seja, regras que limitam o comportamento das pessoas, já que as regras têm por finalidade criar uma estrutura que permita a interação das pessoas na comunidade, nos planos econômico, político e social. As regras podem ser formais, quando são explícitas, tendo poder legítimo para a manutenção da ordem e do desenvolvimento da sociedade. Os exemplos que se poderia dar são a Constituição de um país e as leis e estatutos de uma empresa. As regras informais estão relacionadas aos conjuntos de valores culturais que estão arraigados na sociedade e são passados de geração em geração. No caso das empresas, seria a sua cultura administrativa. Como exemplo, poderiam ser citados costumes, tradições, regras informais, tabus e códigos tácitos de conduta.

O ambiente institucional constitui o que alguns autores definem como as "regras do jogo". Estas promovem o desenvolvimento das atividades econômicas bem como as ações políticas, legais e sociais que governam a base da produção, troca e distribuição (WILLIAMSON, 1996). Os conjuntos de normas e regras delimitam as ações estabelecidas pelo homem, disciplinando suas ações com seus semelhantes e com o mundo, podendo também regulamentar outras instituições, definindo os critérios que serão estabelecidos por meio das duas formas de regras - formais e informais. O ambiente institucional ganha importância quando os custos de transação não

${ }^{8}$ Direito de propriedade são proteções que os cidadãos possuem sobre o uso de seus recursos, seu trabalho e bens (NORTH, 1990).

9 Eficiência ótima de Pareto ocorre quando não se pode realocar o bem para tornar maior o bem-estar de uma pessoa sem que haja a diminuição do de outra (PINDYCK; RUBINFELD, 1994). 
podem ser negligenciados. Não existindo nenhum sistema com esse custo nulo, as instituições devem ser analisadas e consideradas (NORTH, 1994). As instituições criam e delimitam o ambiente onde ocorrerá a transação e onde as organizaçōes irão atuar.

As instituições, juntamente com as restrições padronizadas pela teoria econômica, determinam as oportunidades na sociedade. As organizações são criadas para apropriar-se dessas vantagens e alterar as próprias instituições. A mudança institucional resulta em uma trajetória moldada pela relação simbiótica, envolvendo as instituições e as organizações, como conseqüência das estruturas de incentivos providenciadas pelas instituições. Além disso, deve-se considerar a realimentação dessa simbiose pela percepção e reação às mudanças no conjunto das oportunidades sinalizadas pelo mercado.

A evolução institucional leva também a uma forte relação de dependência com o grau de sua complexidade, seja em relação à configuração estrutural, seja em relação aos propósitos a que deve servir. Acredita Matthews (1986) que uma grande contribuição da $\mathrm{NEI}$ foi demonstrar que, ao mesmo tempo que a inércia é importante para a instituição, ela é o que motiva a sua mudança, incorporando à trajetória de dependência (path dependence) novas concepções institucionais, tornando-se mais complexa e, num segundo momento, novamente inerte, o que assegura estabilidade. Então, com a mudança institucional, ocorre uma renovação, conferindo-se a capacidade de auto-renovação, mas deve existir a segurança da estabilidade, o que pode ser uma dualidade.

A partir das formulações de North, pode-se interpretar o papel do Estado na formação econômica do Brasil e o comportamento dos produtores de café - na época do surgimento das empresas ferroviárias no Brasil. Conseqüentemente, pode-se dar maior realismo para o corpo teórico montado neste estudo. A inserção teórica de North, para o entendimento da dinâmica da economia brasileira, fica bastante ilustrativa, segundo a seguinte interpretação ressaltada por Galvão (1995, p. 772):

... a região SE [Sudeste] configura um caso clássico de como o controle do aparelho do Estado por um grupo social [produtores de café] viesou as políticas econômicas nacionais e distorceu o processo de alocação de recursos em favor desse grupo, terminando por beneficiar mais que proporcionalmente uma seção do território nacional [...] as políticas de valorização [do café no mercado internacional] violaram seriamente o mecanismo de mercado de preços [...] evitou que agentes econômicos importantes fossem penalizados pelos ditames do mercado. 
O fator humano foi também um aspecto importante para o sucesso da formação das empresas de estrada de ferro na Província de São Paulo. O perfil socioeconômico dos produtores de café, no oeste paulista, permitiu que eles assumissem posturas empresariais que ultrapassavam os limites da propriedade de café. Segundo Furtado (1974), a gestão da economia cafeeira a partir de 1850 foi realizada por indivíduos que haviam acumulado certa quantidade de capital no comércio de gêneros alimentícios e de tropas de animais, que passaram a interessar-se pela produção, vindo a constituir a vanguarda da expansão cafeeira. Portanto, o conjunto destes produtores tinha experiência comercial (capital humano) e estava interessado em todas as etapas da gestão: produção e comércio, formando uma nova classe de dirigentes. Nesse sentido, segundo Szmrecsányi x1990), há muitos autores que atribuem considerável importância a essas particularidades dos novos cafeicultores para o sucesso dessa cultura no Brasil.

\section{A Teoria dos Custos de Transação e o Processo de Integração Vertical}

Chandler (1977) elaborou oito proposições sobre a moderna empresa. Contudo, uma delas parece ser fundamental para compreender o comportamento dos cafeicultores brasileiros quando tomaram a decisão de serem acionistas das empresas de estrada de ferro: os acionistas devem ter uma visão de longo prazo, isto é, não devem visar a lucros correntes, mas sim ao aumento do valor da empresa.

Considerando essa proposição, verifica-se que a criação, especialmente, das companhias paulistas de estrada de ferro, apresentadas anteriormente, teve um perfil de investimento de longo prazo. Os investimentos realizados exigiram vultosos volumes financeiros e longos períodos de maturação para a obtenção de lucro. Além dessas características, os investimentos em estrada de ferro estavam atrelados diretamente à atividade cafeeira. O café é uma cultura permanente, na qual se criam expectativas também de longo prazo. Nessas circunstâncias, parece que os cafeicultores assumiram a postura da construção da estrada de ferro como forma de integrar verticalmente as atividades de produção ao transporte. Por outro lado, pode-se contrastar essa situação com a empresa responsável pela constru- 
ção e administração da estrada de ferro D. Pedro II. Esse empreendimento apresentou duas características que o tornaram diferente das companhias paulistas de estrada de ferro. A primeira diz respeito ao horizonte de curto prazo dos investidores; e a segunda é que esses investidores não estavam ligados à atividade cafeeira, mas sim às atividades mercantis. Desse modo, os investidores da estrada de ferro Dom Pedro II esperavam lucros imediatos e compensadores, ficando ausente uma estratégia empresarial de longo prazo.

O processo de integração vertical e as inovações ocorridas no sistema de coordenação das empresas ferroviárias brasileiras permitiram que elas obtivessem redução dos custos de transação, os quais são dimensionados em termos das características básicas da transação, que são: a freqüência, a incerteza e as especificidades ${ }^{10}$ dos ativos (WILLIAMSON, 1985). As linhas férreas paulistas, como já argumentado, estavam estreitamente ligadas ao transporte de café a construção exigia altos investimentos - e visavam ao transporte basicamente de um único produto, cultivado intensivamente em regiões específicas do oeste paulista.

Esse quadro perdurou por longos anos, sendo possivel associar essas características a três especificidades fundamentais da teoria dos custos de transação apresentada por Williamson (1985). Em primeiro lugar, a especificidade do ativo: no transcorrer de quase meio século, o produto preponderante e lucrativo para as companhias ferroviárias foi o café, pois não havia outro produto a ser transportado com escala suficiente que justificasse o volumoso investimento requerido pela ferrovia. Em segundo lugar, especificidade do investimento: a construção da estrada férrea exigia elevados investimentos financeiros. E, finalmente, verifica-se a presença da especificidade de lugar: as zonas servidas pela malha ferroviária eram quase que exclusivamente produtoras de café. Além das especificidades, os atributos de frequêencia com que o café era comercializado utilizando a estrada de ferro e a diminuição das incertezas ocasionadas pelas longas distâncias percorridas em lombo de mulas foram fundamentais para a interação entre estrada de ferro e produtores de café.

O mapa cognitivo apresentado por Williamson (1985) sobre a estrutura de contratos conduz a uma situação de busca de eficiência

\footnotetext{
10 Segundo Williamson (1996), a especificidade do ativo é conceituada como a perda de valor dos ativos envolvidos em determinadas transações caso não se concretize o contrato ou ocorra seu rompimento.
} 
da cadeia produtiva do café, visto que o transporte ferroviário aumenta a rapidez no deslocamento do produto e reduz os custos do produto final. $\mathrm{O}$ alto grau de especificidade do ativo, do investimento e do lugar, como discutido acima, leva à expansão do limite da firma.

Portanto, o processo de integração da atividade cafeeira às empresas ferroviárias foi induzido pela alta especificidade do ativo, do investimento e do lugar. Essas características motivaram a ampliação do limite da empresa agrícola. Os produtores de café constituíam uma organização que influenciava ativamente as instituições, tornando as suas açōes mais seguras e estáveis. Naturalmente, cabe notar que a criação das companhias ferroviárias não foi uma atitude generalizada para todos os produtores de café, mas sim para aqueles que tinham recursos financeiros e capacidade empresarial ${ }^{11}$.

\section{Conclusão}

Neste estudo aplicaram-se as abordagens teóricas de Chandler, Williamson e North para examinar, em primeiro lugar, o surgimento das empresas ferroviárias no Brasil e, em segundo lugar, sob a ótica da economia dos custos de transação, a estratégia dos cafeicultores em integrar verticalmente o sistema de transporte ferroviário à produção de café.

Com base na abordagem teórica de Chandler (1977), procurou-se aprofundar o entendimento acerca da formação e da importância das empresas ferroviárias brasileiras no século XIX. Cabe notar que o perfil da economia americana em meados do século XIX, estudada por Chandler (1977), era bastante diferente do da economia brasileira. Mesmo assim, verificam-se alguns pontos em comum, como o importante papel que as empresas de estrada de ferro em ambos os países tiveram para dinamizar a formação das modernas empresas de capital aberto, segundo a concepção de Chandler.

A abordagem teórica de North (1990), relativa ao papel das instituições, também foi importante para o presente estudo, porque tratou de elementos fundamentais - como, por exemplo, o papel do Estado e o fator humano - para o entendimento do contexto histórico em que surgiram as empresas de estrada de ferro no Brasil. O

${ }^{11}$ Cabe destacar que, em menor escala, houve, também, a participaçäo de investidores alheios à produção de café. 
Estado brasileiro concedia incentivos para que as ferrovias fossem implementadas no território nacional. Essa situação atendia aos interesses dos cafeicultores, que, motivados pelos incentivos estatais, constituíram as primeiras empresas ferroviárias privadas. Dessa maneira, em torno da economia cafeeira, as organizaçōes e as instituições interagiram em uma complexa relação simbiótica.

A abordagem da economia dos custos de transação discutida intensivamente por Williamson $(1975,1985,1996)$ sugere que os produtores de café que participavam das empresas acionárias da estrada de ferro tinham motivações para ampliar os limites de suas firmas (fazendas), integrando-se com o sistema de transporte ferroviário.

Por fim, constata-se que as abordagens teóricas apresentadas podem ser convenientemente aplicadas para analisar o processo de formação da moderna empresa ferroviária brasileira no século XIX, em muitos de seus aspectos.

\section{Referências bibliográficas}

BARAT, J. A evolução dos transportes no Brasil. Rio de Janeiro: FIBGE/PEA, 1978. CHANDLER, A. D. Jr. Strategy and structure: chapters in the history of the industrial enterprise. Cambridge, MA: The MIT Press, 1962.

CHANDLER, A. D. Jr. The visible hand: the managerial revolution in American business. Cambridge, MA: The Belknap Press of Harvard University Press, 1977.

DEBES, C. A caminho do Oeste: história da companhia paulista e estrada de ferro. São Paulo: Bentivegna, 1968. (Edição comemorativa do centenário de fundação da Companhia Paulista).

MCCRAW, T. (Org.). Alfred Chandler: ensaios para uma teoria histórica da grande empresa. Rio de Janeiro: FVG, 1998.

DELFIM NETTO, A. O problema do café no Brasil. 1959. Tese (Doutorado) - FEA, Universidade de São Paulo, São Paulo, 1959.

FARINA, E. M. M. Q.; AZEVEDO, P. F.; SAES, M. S. M. Competitividade: mercado, Estado e organizações. São Paulo: Singular, 1997. 286 p.

FURTADO, C. Formação econômica brasileira. São Paulo: Nacional, 1974.

FURTADO, C. Análise do "modelo" brasileiro. São Paulo: Civilização Brasileira, 1982.

GALVÃO, O. J. A. "Federalismo desigual, políticas cafeeiras e equilíbrio espacial parentiano". In: ENCONTRO DE ECONOMISTAS DE LÍNGUA PORTUGUESA, 2., Rio de Janeiro, 1995. Anais... Rio de Janeiro: UFRJ, 1995. p. 764-775. 
MATOS, O. N. Café e ferrovias. São Paulo: Alfa-Omega/Sociologia e Política, 1974. MATTHEWS, R. C. O. "The economics of institution and the source of growth". Economics Journal, New York. v. 96, n. 384, p. 903-918, Dec. 1986.

NORTH, D. Custos de transação, instituições e desempenho econômico. Rio de Janeiro: Instituto Liberal, 1994. 38 p.

NORTH, D. C. Institutions, institutional change and economic performance. Cambridge: Cambridge University Press, 1990.

NORTH, D. C. "Institutions". Journal of Economic Perspectives, Minessota, v. 5, n. 3, p. 97-112, Winter 1991.

PINDYCK, R. S.; RUBINFELD, D. Microeconomia. São Paulo: Makron Books, 1994. $967 \mathrm{p}$.

SAES, F. A. M. As ferrovias de São Paulo: 1870-1940. São Paulo: Hucitec/INL-MEC, 1981. (Coleçāo Estudos Históricos).

SAES, F. A. M. A grande empresa de serviços públicos na economia cafeeira. São Paulo: Hucitec, 1986.

SZMRECSÁNYI, T. Pequena história da agricultura no Brasil. São Paulo: Contexto, 1990.

TOPIK, S. A presença do Estado na economia politica do Brasil de 1889 a 1930 . São Paulo: Record, 1987.

VEIGA, T. G. Trem, terra e trabalho: a Sāo Paulo Railway. São Paulo: PUC/SP, 1991. (dissertação de mestrado)

WILLIAMSON, O. E. The economic institutions of capitalism. New York: Free Press, 1985.

WILLIAMSON, O. E. The mechanism of governance. New York: Oxford University Press, $1996.429 \mathrm{p}$.

WILLIAMSON, O. E. Market and hierarchies. New York: Free Press, 1975. 286 p.

WILLIAMSON, O. E. The economic institutions of capitalism. New York: Free Press, $1985.450 \mathrm{p}$. 